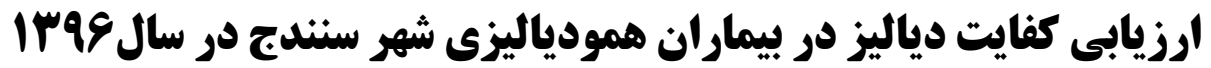

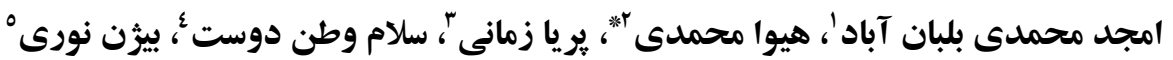

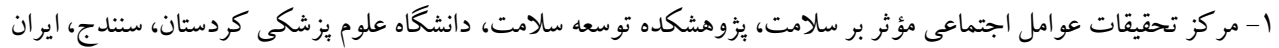

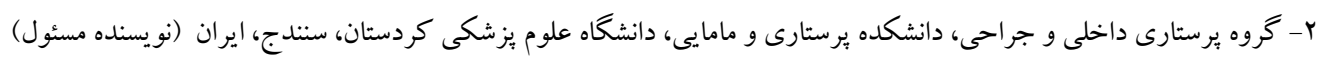
ايميل: Hiva.nursing@gmail.com

تلفن: (1)

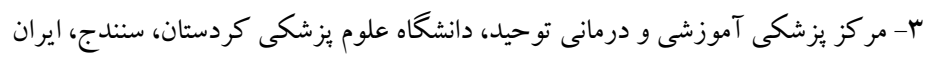

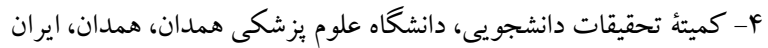

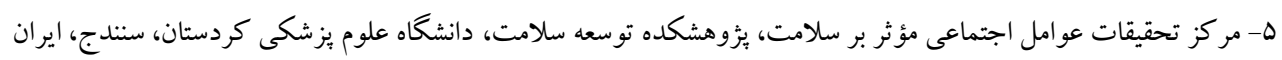

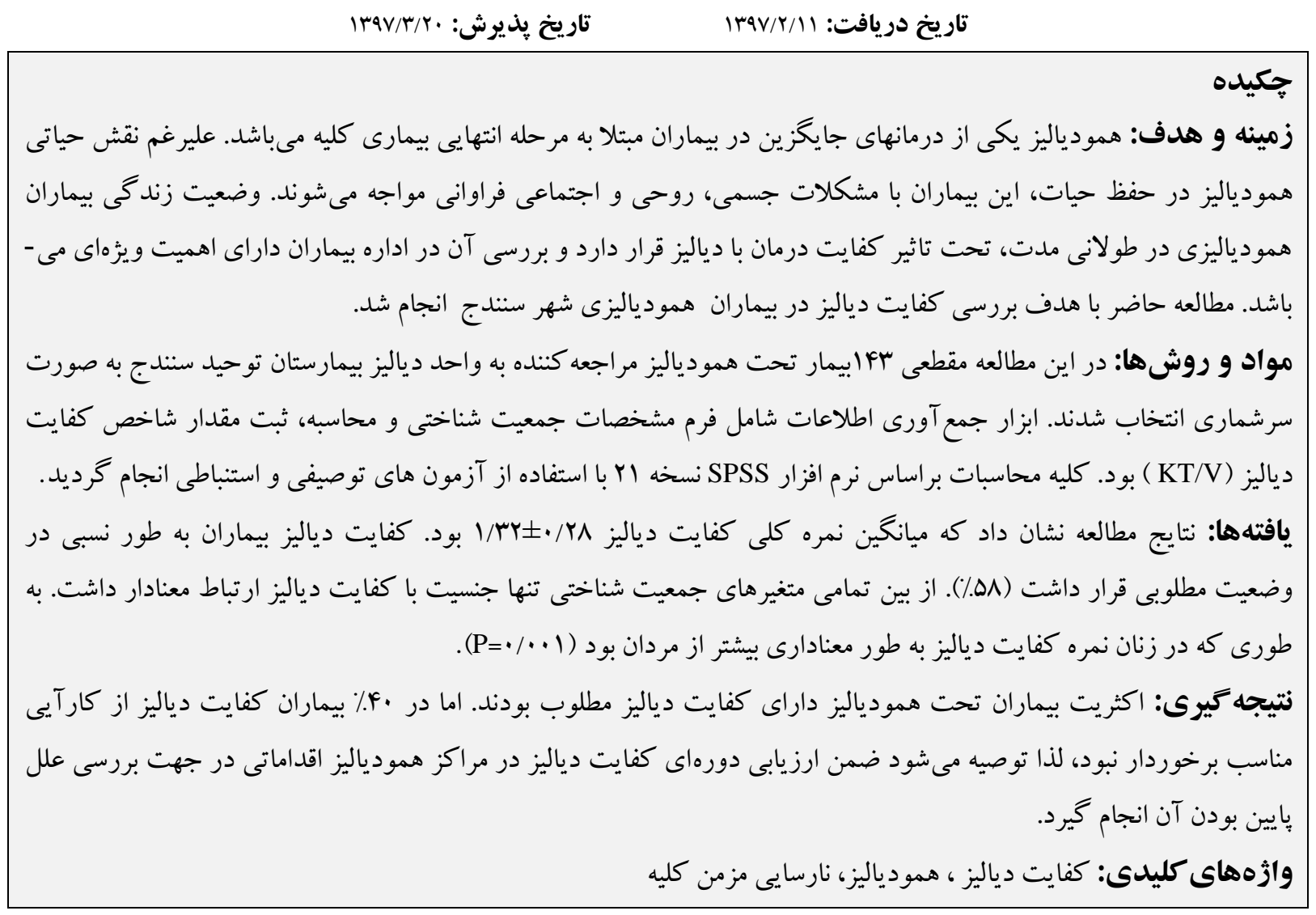


استفاده از معيارهايى مانند درصد نسبى كاهش اوره و KT/V استفاده شده است (·1). در حال حاضر ماضئ معتبرترين و مشهورترين روش سنجش و ارزيابى

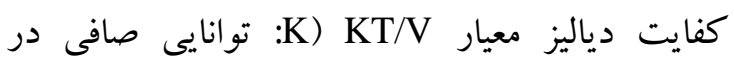
جاككسازى اوره، T: مدت زمان انجام همودياليز بر حسب دقيقه، V: حجم توزيع اوره در مايعات بدن كه بستخى به قد، جنس و وزن دارد) مىباشد، كه طبق

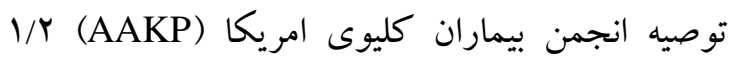
دلالت بر انجام همودياليز با كفايت مناسب KT/V مىباشد (11). همجينين مطالعه انجام گرفته در اين زمينه نشان داده است كه به ازاى افزايش // / • واحد در

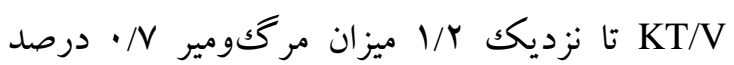
كاهش مىيابد (Y) (Y). عليرغم ييشرفتهاى بسيار در كشورهاى ييشرفته و در جوامع درحال توسعه از جمله ايران همجنان درصد بالاى از بيماران KT/V > I/ دارند و از كفايت دياليز با سطح بايين بهره مىبرند

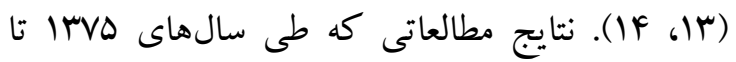
هوسا در مراكز مختلف دياليز سطح كشور انجام شده است، نشان داد كه بيش از •ه درصد بيماران از كفايت دياليز نامطلوب (KT/V<//Y) برخوردار بودند (ه) (1).

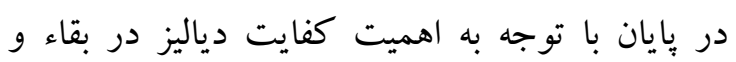

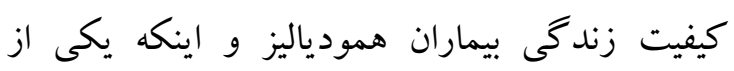
وظايف برستاران شاغل در بخشهاى همودياليز به عنوان نيروهاى متخصص علاوه بر ارائهى خدمات درمانى و مراقبتى توجه به كيفيت دياليز ارائهى اين

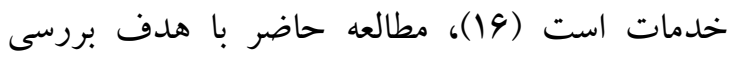
كفايت دياليز در بيماران همودياليزى انجام شد. مقلdمه

همودياليز يكى از درمانهاى جايخزين در بيماران مبتلا به مرحله انتهايى بيمارى كليه (ESRD) مىباشد (1)، به طورى كه در حال حاضر بيش از ...." با بيمار در سطح كشور تحت درمان با همودياليز قرار دارند و ماهيانه براى بيماران در حدود ... . 10 جلسه همودياليز انجام مىشود (Y). عليرغم نقش حياتى همودياليز در حفظ حيات بيماران مبتلا به ESRD، اين بيمارى عوارض متعددى نظير خستخى مفرط، افسردگى، نابارورى و اختلال در عملكرد جنسى، آنمى، مشكلات عضلانى_اسكلتى، اضطراب، بيمارىهاى قلبى - عروقى

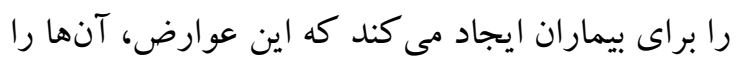
با مشكلات جسمى، روحى و اجتماعى فراوانى روبرو مى كند (r-U). بهطورى كه اين مشكلات مىتواند بر روى برنامه شغلى، وضعيت استخدامى، اقتصادى،

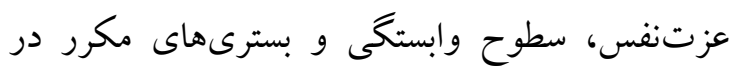

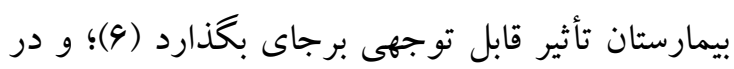

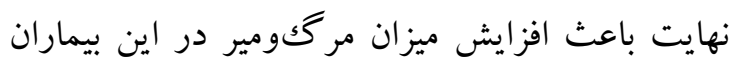

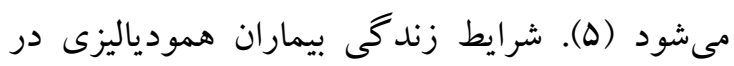
طولانى مدت تحت تأثير كفايت درمان با دياليز قرار

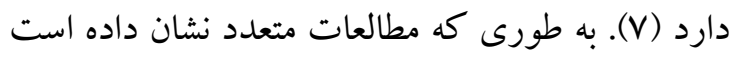
كه افزايش در كارايى كفايت دياليز مىتواند باعث ارتقاء سطح سلامتى، افزايش اميد به زندگى و كاهش دانش در ميزان مر گكومير بيمار ان شود (س، ش). بنابراين افزايش كفايت دياليز يكى از خالشهاى

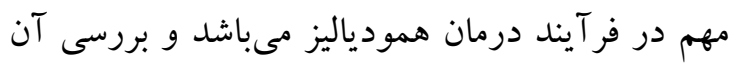
در اداره بيماران داراى اهميت ويزهاى مىباشد (1) 9. 9). در همين راستا براى تعيين كفايت دياليز از روشهايى

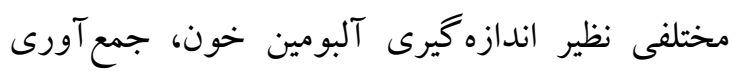
مايع دياليز، كليرانس مولكولهاى متوسط مثل ويتامين

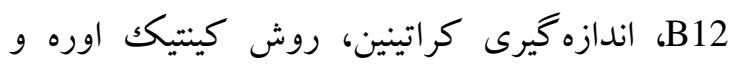


بيمار پِ از انجام همودياليز (وزن خشك) مىباشد (11)، محاسبه و در فرم مربوط به هر كدام از بيماران ثبت شد. كرفتن نمونهاى خون و سنجش كفايت دياليز براى بيماران به صورت روتين ماهانه در بخش

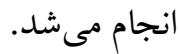

در بايان دادهها وارد نرمافزار SPSS نسخه اب شد، با استفاده از آمار توصيفى (ميانگين و انحر اف معيار) و

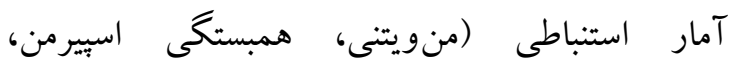
كروسكال واليس) مورد تجزيهوتحليل قرار گرفت. ه • P • معنى Pار در نظر كرفته شد.

يافته ها

در اين مطالعه تعداد

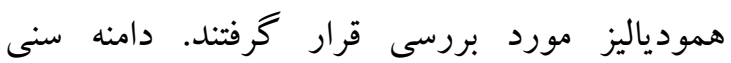

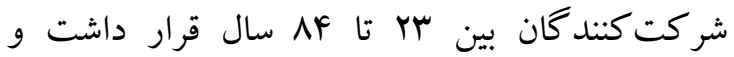

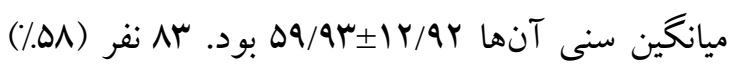
جمعيت را مردان تشكيل مىدادند. اكثريت شركتكنند كان متأهل، از نظر تحصيلات بىسواد و فاقد شغل بودند. از نظر بيمارى زمينهاى •V٪٪ بيماران مبتلا به

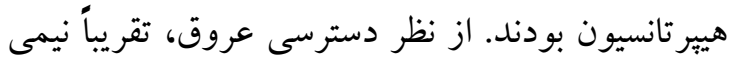
از بيماران داراى فيستول شريانى-وريدى (VI/V/ه) بودند (جدول ()). ميانكين نمره كفايت دياليز (KT/V)

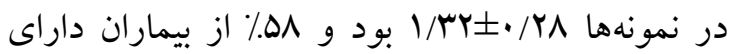
كفايت دياليز مطلوب بودند (جدول r).

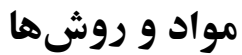

اين مطالعه مقطعى در تابستان و9 11 انجام شد. جامعه يثزوهش شامل بأl بيمار همودياليزى در مركز آموزشى - درمانى بيمارستان توحيد شهر سنندج بود كه به صورت سرشمارى انتخاب شدند. معيارهاى ورود به مطالعه شامل سابقه حداقل r ماه از شروع دياليز، هوشيارى كامل و توانايى برقرارى ارتباط كلامى و معيارهاى خروج نيز عدم تمايل همكارى بود. در جهت رعايت موازين اخلاقى ابتدا به بيماران اطلاعات لازم در مورد اهداف مطالعه داده شد و رضايت آكاهانه

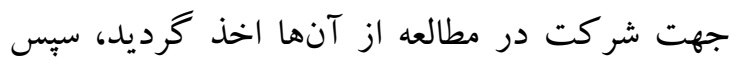
فرم اطلاعات جمعيت شناختى به صورت بىنام بين آنها توزيع شد. ابزار جمع آورى اطلاعات شامل فرم اطلاعات جمعيت شناختى و محاسبه، ثبت مقدار كT/ KT/V بود. فرم اطلاعات جمعيت شناختى 9 سؤال (سن، جنس، تأهل، تحصيلات، اشتغال، بيمارى زمينهاى، مصرف سيخار، نوع دسترسى عروق و سابقه همودياليز ) رادر بر مى گرفت. براى اندازهيرى BUN قبل از دياليز، نمونه خون از مسير شريانى بلافاصله قبل از شروع همودياليز گرفته

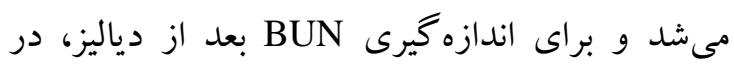
دقايق بايانى همودياليز ابتدا دور پيمٍ دستگاه به مقدار

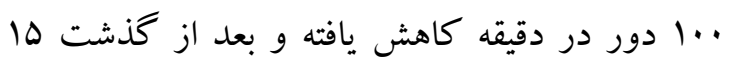
ثانيه نمونه ديخرى از مسير شريانى گرفته مىشد (11)

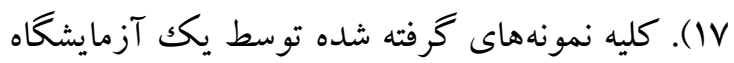
و يكك نوع كيت بررسى گرديد. بس از اندازه گيرى و

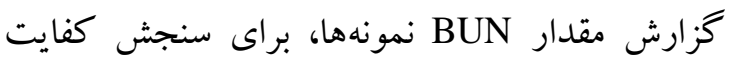

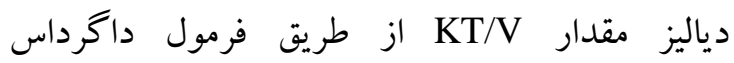
كه (KT/W=-ln(R-0/008T) + (4-3/5R)*UF/V) در اين فرمول R نسبت كاهش اوره (URR)، T مدت زمان انجام همودياليز، UF اضافهوزن بيمار و V وزن 


\begin{tabular}{|c|c|c|c|}
\hline درصد & فراوانى & \multicolumn{2}{|c|}{ مشخصات فردى } \\
\hline$\Delta \Lambda$ & $\wedge \mu$ & 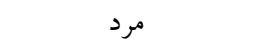 & \multirow{2}{*}{ جنس } \\
\hline Fr & 4. & زن - ان & \\
\hline$\wedge 9$ & irv & متأهل & \multirow{2}{*}{ 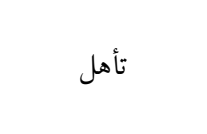 } \\
\hline 11 & 19 & مجرد ل & \\
\hline $91 / 0$ & $\wedge$ & 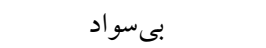 & \multirow{3}{*}{ سطح تحصيلات } \\
\hline$r Y / 9$ & FV & دييلم و زير دييلم & \\
\hline $0 / 4$ & $\wedge$ & دانشگاهى & \\
\hline $99 / 9$ & $1 \ldots$ & بيكار & \multirow{3}{*}{ 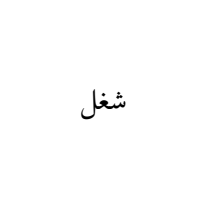 } \\
\hline $9 / \pi$ & 9 & 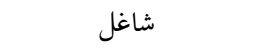 & \\
\hline$r \mu / \Lambda$ & re & بازنشسته & \\
\hline$q \cdot / r$ & $1 \mathrm{rq}$ & خير & \multirow{2}{*}{ سيخار } \\
\hline $9 / \wedge$ & if & بله & \\
\hline $11 / r$ & 19 & 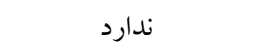 & \multirow{6}{*}{ بيمارى زمينهاى } \\
\hline$\Lambda / \mathcal{F}$ & ir & ديابت & \\
\hline $\mathrm{rV} / \mathrm{A}$ & $\Delta F$ & فشارخون & \\
\hline$\cdot / V$ & 1 & كلومرونفريت & \\
\hline $9 / \wedge$ & if & كليه يلى كيستيكك & \\
\hline$M Y / Y$ & 49 & ديابت و فشارخون & \\
\hline$\Delta 1 / V$ & $v F$ & فيستول شريانى - وريدى & \multirow{2}{*}{ نوع دسترسى عروق } \\
\hline FN/ & 99 & كاتتر وريد مركزى & \\
\hline \multicolumn{3}{|c|}{$\Delta q / q r \pm I r / q r$} & سن (سال) \\
\hline & $r \pm$ & & سابقه همود ياليز (سال) \\
\hline
\end{tabular}

و سابقه سيگار كشيدن (P=•/ F) اختلاف معنادارى وجود نداشت. بر اساس آزمون كروسكال واليس اختلاف معنادارى بين كفايت دياليز با سطح تحصيلات (P=•/IV) مشاهده نشد. كفايت دياليز در سنين مختلف (P=•/AV) با هم تفاوت معنادارى نداشتند (P=・V) آزمون همبستخى اسييرمن نشان داد كه سابقه انجام
در تجزيهو تحليل آمارى به علت توزيع غير نرمال متغير كفايت دياليز از آزمونهاى غير بارامتريك استفاده شد. در ابتدا آزمون من ويتنى نشان داد كه بين كفايت دياليز و جنسيت ارتباط معنادارى وجود دارد

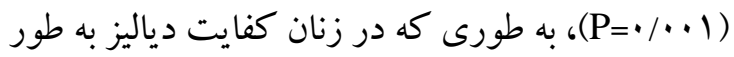
معنادارى بيشتر از مردان بود (q// = = KT/V در مقابل ( $\mathrm{P}=\cdot$ (KT/V=l/YF 
ويتنى مشخص شد كه بين نوع دسترسى عروق و نمره

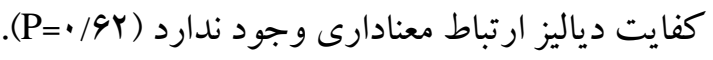

همودياليز در ميزان كفايت دياليز تأثيرى ندارد (P=•/49) دياليز و نوع دسترسى عروق با استفاده از آزمون من -

\begin{tabular}{|c|c|c|c|c|}
\hline درصد & فراوانى & \multicolumn{3}{|c|}{ كفايت دياليز } \\
\hline$\Delta \wedge$ & $\wedge r$ & $\geq 1 / r$ & مطللوب & \\
\hline pr & 4. & $<1 / r$ & 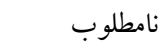 & \\
\hline \multicolumn{2}{|c|}{$1 / 49 \pm \cdot / 49$} & ميانكين (انحراف معيار) & مردان & \\
\hline \multicolumn{2}{|c|}{$1 / \Gamma q \pm \cdot / q^{\prime}$} & ميانكين (انحراف معيار) & زنان & جنسيت \\
\hline \multicolumn{2}{|c|}{$1 / r r \pm \cdot / r \Lambda$} & ميانكين (انحراف معيار) & كل & \\
\hline
\end{tabular}

در مطالعه حاضر ارتباط شاخص كفايت دياليز با متغيرهاى دمو گرافيكى و بالينى مورد بررسى قرار

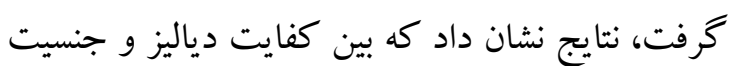
ارتباط معنادارى وجود دارد، بدين معنى كه شاخص

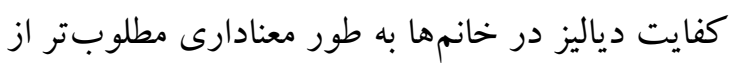
مردان بود كه بعضى از مطالعات نتيجه مطالعه حاضر را تائيد كردهاند (T، Y Y، سY). احتمال مىرود اين مسئله مربوط به استفاده صافى دياليز مشابه در هردو جنس و در نتيجه انجام دياليز بهتر براى زنان با توجه به جثه

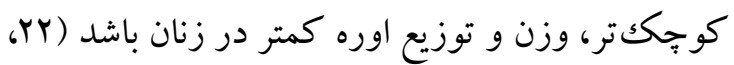
ك:ا كفايت دياليز و جنسيت ارتباط معنادارى وجود ندارد

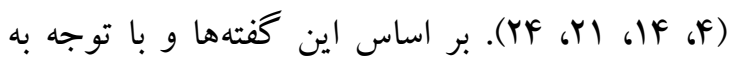
نتايج متفاوت به نظر مىرسد كه براى روشتر شدن قضيه نياز به انجام مطالعه در اين زمينه باشد. در ارتباط

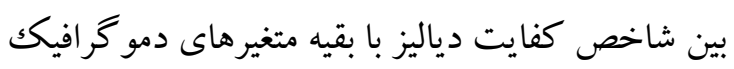
(سن، سطح تحصيلات، سابقه سيكار كشيدن، تأهل،

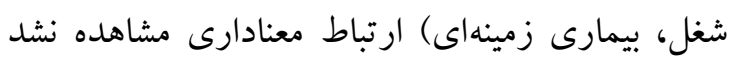
كه جندين مطالعه نتيجهى مطالعه حاضر را حمايت كردند (سا، 19). از نظر داشتن نوع دسترسى عروقى نتايج حاكى از اين بود كه تقريباً نيمى از بيماران داراى

\section{بحث و نتيجه كيرى} نتايج مطالعه اخير در خصوص ديرى ميزان كفايت دياليز حاكى از آن بود كه ميانخين اين شاخص در مريز

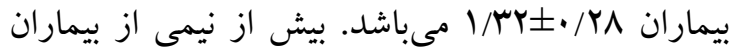
داراى KT/V صورت مطلوب بوده است. گرجهه درصد بالايى از بيماران از شاخص بالاى KT/V برخوردار بودند، ليكن در \% Fr\% بيماران كفايت دياليز نامطلوب (KT/V) بود. نتايج جندين مطالعه نشان داد كه اكثريت بيماران همودياليزى در سطح كشور از كفايت مطلوب برخوردار هستند كه با مطالعه ما همسو بود (سا، F، 1)؛

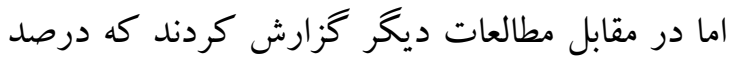
بيشتر بيماران از كفايت دياليز ويايينتر از حد مطلوب بهره مىبرند (1) 19-19). البته شايان ذكر است در مطالعاتى كه گزارش كرده بودند بيشتر بيماران داراى كفايت دياليز بايين مىباشند از نظر زمان انجام مطالعه قديمىتر بودند كه اين خود نشان از ارتقاء سطح مراقبتى -درمانى، توجه بيشتر مديران و افزايش امكانات براى بيماران همودياليزى در بخشهاى همودياليز سطح

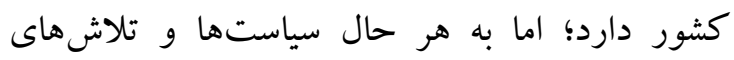
سيستم سلامت بايد در راستاى باشد كه همه بيماران همودياليزى از كفايت دياليز مطلوب برخوردار باشند. 
و انجام اقدامات درمانى - مراقتى در جهت اصلاح آن را دارد. همجِين در اين مطالعه معلوم شد كه كفايت دياليز در زنان به طور معنادارى بيشتر از مردان بيشتر مىباشد و نوع دسترسى عروق تأثيرى در شاخص كفايت دياليز ندارد كه به نظر مىرسد براى روشن شدن قضيه نياز به مطالعات بيشترى مىباشد.

\section{تشكر و قدردانى}

اين مطالعه منتج از طرح تحقيقاتى به شماره IM99/AV دانشخاه علوم يزشكى كردستان مىباشد IR.MUK.REC كه بدينوسيله از كليه مسئولين و كاركنان يزوهش دانشگاه و كليه بيماران گرامى كه ما را در انجام اين مطالعه يارى نمودند، سپاسگز اريم.
شالدون و نيمهى ديكر فيستول شريانى -وريدى داشتند كه در بررسى ارتباط بين شاخص كفايت همودياليز و نوع دسترسى عروق ارتباط معنادارى مشاهده نشد. مطالعات متعددى با مطالعهى حاضر همسو بودند (س)، Y)، اما در مقابل مطالعات ديخر نتيجه گرفتند كه كفايت دياليز در روش فيستول شريانى وريدى به مراتب بيشتر از شالدون دائم مىباشد (Y9، YV). با توجه به اين نتايج متفاوت به نظر مىرسد كه نياز به انجام مطالعات بيشتر در اين زمينه مىباشد. نتايج مطالعه حاضر نشان داد كه اكثريت بيماران داراى كفايت همودياليز مطلوب مىباشند اما در مقابل در حدود ·٪/ آنها از كفايت دياليز با كيفيت ياينى برخوردار بودند كه اين نياز به بررسى و بيدا كردن علل

\section{References}

1. Bjorg Th, Keith MS, Molly AF, Paul SM, Amy WW. Are there alternatives to hemodialysis for the elderly patient with End-Stage Renal Failuure?. Myo Clin Proc 2012; 87(6): 514-160.

2. Hojjat M. Hemodialysis adequacy in patients with chronic renal failure. Iran J Crit Care Nurs 2009; 2(2): 61-6.

3. Rezaiee O, Shahgholian N, Shahidi S. Assessment of hemodialysis adequacy and its relationship with individual and personal factors. Iranian journal of nursing and midwifery research. 2016; 21(6): 577. [Persian]

4. Mohammadi H. Relationship between dialysis adequacy and sleep quality in hemodialysis patients. Journal of Urmia Nursing And Midwifery Faculty. 2018; 16(1): 30-7 .[Persian]

5. Jaber BL, Lee Y, Collins AJ, Hull AR, Kraus MA, McCarthy J, et al., Effect of daily hemodialysis on depressive symptoms and postdialysis recovery time: Interim report from the Freedom (Following Rehabilitation, Economics and Everyday-Dialysis Outcome Measurements) Study. Am J Kidney Dis 2010; 56(3): 531-9.

6. Tayyebi A, Savari S, Nehrir B, Rahimi A, Eynollahi B. The effect of Vitamin B12 supplemention on fatigue in hemodialysis patients. Iran J Crit Care Nurs 2013; 6(5): 39-48 .

7. Merlino G, Piani A, Dolso P, Adorati M, Cancelli I, Valente M, Gigli GL. Sleep disorders in patients with end-stage renal disease undergoing dialysis therapy. Nephrol Dial Transplant 2006; 21(1):184-190.

8. Borzou R, Ghlyaf M, Amini R, Zandiyan M, Torkaman B. Evaluation of dialysis adequacy in hemodialysis Ekbatan Hospital. Hamadan 2006; 13(4): 53-7 .[Persian]

9. Lazzaretti CT, Carvalho JG, Mulinari RA, Rasia JM. Kidney transplantation improves the multidimensional quality of life. Transplantation Proceedings. 2004; 36(4): 872-3. 
10. K/DOQI Clinical Practice Guidelines and Clinical Practice Recommendations 2006 Updates hemodialysis adequacy peritoneal dialysis adequacy vascular access. American Journal Kidney Diseases. 2006; 48(Supply) 10:51.

11. Daugirdas JT, Kjellstrand CM, Daugirdas JT, Blake PG, Ing TS. Prescrição de hemodiálise crônica: uma abordagem da cinética da uréia. Daugirdas JT, Ing TS. Man diál.. Rio de Janeiro: Med si. 2003.

12. Wanoewski J. Lindholm B. Fractional solute removal and $\mathrm{KT} / \mathrm{V}$ in different modalities of renal replacement therapy. Blood Purification 2004; 22 (4) 367-376.

13. Scribenr B. Ordpoulos M. The hemodialysis product (HOP): A Better Index of Dialysis Adequacy tan KT/V. Dialysis \& Transplantation. 2002; 31(1) 13-15.

14. Monfared A. Orang Pour R. Kohani M. [Evaluation of hemodialysis adequacy on patients undergoing hemodialysis in Razi Hospital in Rasht]. Journal of Medical Faculty Guilan University of Medical Sciences 2008; 65 (17) 44-49. [Persian]

15. Barzegar H, Moosazadeh M, Jafari H, Esmaeili R. Evaluation of dialysis adequacy in hemodialysis patients: A systematic review. Urology journal. 2016; 13(4): 2744-9.

16. Farhadi M, Dadgari F, Farsi Z, Dadgari A. Dialysis adequacy in chronic hemodialysis patients in a military hospital. EBNESINA. 2015; 17(2): 36-42. [Persian]

17. Culleton BF. Hemodialysis Clinical Practice Guidelines for the Canadian Society of Nephrology. J Am Soc Nephrol 2006; 17(3): 1-27.

18. Moghaddam ZG, Sharifi S, Raeese A, Fard MY, Mirzaee K, Bahraine M. Investigation of Hemodialysis Adequacy in Patients Undergoing Hemodialysis in the Shohada Hospital in Bushehr. Iran South Med J. 2016; 18(6): 1236-44. [Persian]

19. Ghafourifard, M., et al., Effect of sodium dialysate variation in combining with ultra filtration on intradialytic hypotension and intradialytic weight gain for patients on hemodialysis. J Mazand Univ Med Sci, 2009; 19(72): 19-26. [Persian]

20. Delavari , A., A. Sharifian, and E. Rahimi Assessment quality of dialysis in 3 center of dialysis in Kordestan. Kordestan Univ Med Sci J, 2001.5(20):18-22. [Persian]

21. Beladi Mousavi SS, Hosseini Nejad K, Zeraati AA. The Evaluation of Dialysis Adequacy by KT/V in Hemodialysis Patients. Jundishapur Scientific Medical Journal. 201; 11(1): 43-48 .[Persian]

22. Mogharab M, Madarshahian F, Rezai N, Mohammadi A, et al. Dialysis adequacy in chronic hemodialysis patients in educational center Vali-Asr in Birjand. Journal of Birjand University. 2010; 17(3): 206-14. [Persian]

23. Azita ZM, Babak H, Reza G, Fatemeh M. Dialysis adequacy in chronic hemodialysis patients in Shohada Ashayer Hospital, Khorramabad, Lorestan, Iran. Yafte 2016;18(4).13-20. [Persian]

24. Jessica EM, Csaba PK, Allen RN, Rajnish M, Elani S, David VW, et al. Association of hemodialysis treatment time and dose with mortality and the role of race and sex. AMJ Kidney Dis 2010; 55(1): 100-12.

25. Esmaeilivand M, Mohammadi M, Khatony A, Najafi F. Comparison of dialysis adequacy in permanent catheter, fistula, and graft vascular access types. Journal of Babol University of Medical Sciences. 2016;18(3):14-8. [Persian]

26. Kukavica N, Resic H, Sahovic V. Comparison of complications and dialysis adequacy between temporary and permanent tunnelled catheter for haemodialysis. Bosn J Basic Med Sci. 2009; 9(4): 265-70.

27. Canaud B, Leray-Moragues H, Kerkeni N, Bosc JY, Martin K. Effective flow performances and dialysis doses delivered with permanent catheters: a 24-month comparative study of permanent catheters versus arterio-venous vascular accesses. Nephrol Dial Transplant. 2002; 17(7): 1286-92. 


\title{
Evaluation of hemodialysis adequacy in hemodialysis patients in Sanandaj in 2017
}

\author{
Amjad Mohammadi Bolbanabad ${ }^{1}$, Hiwa Mohammadi ${ }^{2 *}$, Pariya Zamani ${ }^{3}$, Salam Vatandost ${ }^{4}$, \\ Bijan Nouri $^{5}$ \\ 1- Social Determinants of Health Research Center, Research Institute for Health Development, Kurdistan \\ University of Medical Sciences, Sanandaj, Iran \\ 2- Department of Medical Surgical Nursing, Faculty of Nursing and Midwifery, Kurdistan University of \\ Medical Sciences, Sanandaj, Iran (Corresponding Author)

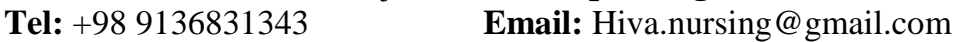 \\ 3- Tohid Hospital, Kurdistan University of Medical Sciences, Sanandaj, Iran \\ 4- Student Research Committee, Hamadan University of Medical Sciences, Hamadan, Iran \\ 5- Social Determinants of Health Research Center, Research Institute for Health Development, Kurdistan \\ University of Medical Sciences, Sanandaj, Iran
}

Received: 1 May 2018

Accepted: 10 June 2018

\begin{abstract}
Background \& Aim: Hemodialysis is one of the alternative therapies in patients with end stage renal disease. Despite the vital role of hemodialysis in maintaining life, these patients face a lot of physical, mental and social problems. The hemodialysis status of patients in the long run is influenced by the adequacy of hemodialysis treatment and its analysis is particularly important in the management of patients. The present study was conducted to determine the adequacy of hemodialysis in hemodialysis patients in Sanandaj.

Materials \& Methods: In this cross-sectional study, 143 patients undergoing hemodialysis referring to the dialysis ward of Tohid Hospital in Sanandaj city were selected by census. The data collection tool comprised of demographic characteristics and calculation, recording the value of the hemodialysis adequacy index $(\mathrm{KT} / \mathrm{V})$. All calculations were performed using SPSS 21 software using descriptive and inferential tests.

Results: The results of the study showed that the average total score of hemodialysis adequacy was $1.32 \pm 0.28$. Patient hemodialysis adequacy was in a favorable situation (58\%). Among all demographic variables, only gender had significant correlation with hemodialysis adequacy. In women, hemodialysis adequacy score was significantly higher than males $(\mathrm{P}=0.001)$.
\end{abstract}

Conclusion: The majority of hemodialysis patients had satisfactory hemodialysis adequacy. However, in $40 \%$ of hemodialysis patients, the adequacy of hemodialysis was ineffective. Therefore, it is recommended that a periodic assessment of the adequacy of hemodialysis in hemodialysis centers should be undertaken to investigate its underlying causes.

Keywords: dialysis adequacy, hemodialysis, chronic renal failure 